\title{
Evaluation of the airphx advance oxidation system in controlling healthcare-associated infections on various surfaces
}

\begin{abstract}
The effectiveness of reactive oxygen species (ROS) generating airPHX equipment for reducing bacterial populations of Clostridium difficile, Methicillin Resistant Staphylococcus aureus (mRSA) and Pseudomonas aeruginosa on three (3) common contact surfaces; stainless steel (Austenitic 316), plastic (PVC) and linoleum (floor tile) were studied. Antimicrobial resistant pathogens pose an ongoing and increasing challenge to hospitals because they cause healthcare-associated infections (HAIs) during clinical treatment of patients. Coupons of stainless steel, plastic and linoleum were inoculated with each organism placed inside an experimental chamber were continuously treated with ROS for eight different hour increments from an airPHX advanced oxidation generator. ROS levels were continuously monitored prior to removing coupons for microbiological testing. Control coupon were similarly placed in the chamber and held at environmental conditions to determine natural decay of microbial populations through time. Stainless steel coupon results after $0.5 \mathrm{~h}$ of ROS treatment Clostridium difficile Methicillin Resistant Staphylococcus aureus (mRSA) and Pseudomonas aeruginosa saw a 4.21-log, 4.42-log and 4.26-log destruction respectively. After $12 \mathrm{~h}$ exposure these same organisms yielded a 6.87- $\log , 7.17-\log$ and 7.71-log reduction, respectively. The other contact surfaces, plastic and linoleum displayed similar log reduction. These findings reveal that ROS treatment using the airPHX unit significantly reduces these three HAI's on common health care contact materials to $>4.2-\log$ destruction after a $0.5 \mathrm{~h}$ exposure.
\end{abstract}

Keywords: antimicrobial, patients, healthcare, infections, prevention, ozone
Volume I Issue 2 - 2017

\author{
Rick Falkenberg \\ Nestle Nutrition R \& D Center, USA
}

\begin{abstract}
Correspondence: Rick Falkenberg, Ph.D, CFS Scientific Air Solutions, 1635 Freedom Court, Turlock, California, USA, Postal code 95382, Tel 209-485-8484,

Email Ricky.Falkenberg@rd.nestle.com
\end{abstract}

Received: July 22, 2017 | Published:September 13, 2017
Abbreviations: mRSA, methicillin resistant staphylococcus aureus; HAIs, Healthcare-associated infections; UV, ultra violet; $\mathrm{RH}$, relative humidity; T, temperature; PVC, polyvinyl chloride; PP, polypropylene; PE, polyethylene; PS, polystyrene; PET, polyethylene terephthalate; PA, polyimide; PC, polycarbonate; ABS, acrylonitrile butadiene; PEEK, polyether ether ketone; PU, polyurethane

\section{Literature review}

Antimicrobial resistant pathogens pose an ongoing and increasing challenge to hospitals because they cause healthcareassociated infections (HAIs) during clinical treatment of patients. In addition, these pathogens pose a difficult challenge in the prevention of its cross-transmission and contamination. Clostridium difficile, Methicillin Resistant Staphylococcus aureus (mRSA) and Pseudomonas aeruginosa have become important problems in the medical field in the past decade because of their resistance to commonly used disinfectants. Ozone has been widely evaluated as a method to disinfect against strains of this bacterium and viruses with variable results.

An allotropic modification of oxygen, ozone is a bluish gas with pungent and characteristic odor. It has a molecular weight of 48 , boiling point of $2,111.9^{\circ} \mathrm{C}$, and melting point of $2,192.8^{\circ} \mathrm{C}$ at $1 \mathrm{~atm} .{ }^{1}$ Ozone weighs ca. $0.135 \mathrm{lb} / \mathrm{ft}^{3}$ and has an oxidation potential of $22.07 \mathrm{~V}$, which compared to that of hypochlorous acid $(21.49 \mathrm{~V})$ or chlorine $(21.36 \mathrm{~V})$ is very high. ${ }^{2}$

Ozone is naturally formed by the action of solar UV irradiation on oxygen in small amounts $(0.05 \mathrm{mg} /$ liter $)$ in the stratosphere.
Small amounts of ozone are also formed in the troposphere as a byproduct of photochemical reactions between oxygen, hydrocarbons, and nitrogen that are released from automobile exhausts, industries, forests, and volcanic action. Ozone is very unstable and decomposes quickly in the air. ${ }^{3}$

Ozone is artificially generated at low concentrations $(0.03 \mathrm{ppm})$ from oxygen in the air by radiation of $185-\mathrm{nm}$ wavelength, emitted by high transmission UV lamps, ${ }^{4}$ but is the corona discharge method the most widely used to produce large amounts of ozone (Figure 1). A high-voltage alternating current is applied across a discharge gap in the presence of air or oxygen, exciting oxygen electrons and inducing the oxygen molecules to split and combine with other oxygen molecules to form ozone, $\mathrm{O}_{3}$ Ozone production varies depending on voltage, current frequency, dielectric material property and thickness, discharge gap, and absolute pressure within the discharge gap.

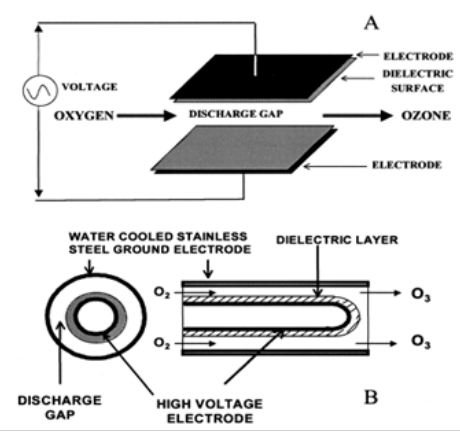

Figure I Conceptual design of corona discharge ozone generator (Rose, 1972). A) Basic configuration, B) tube-type generator unit. 
In addition to photochemical and electric discharge methods, ozone can be produced by chemical, thermal, chemo nuclear and electrolytic methods. $^{3}$ In the upper atmosphere, high-energy UV irradiation helps degrade ozone molecules. Ozone is converted to oxygen in the process and absorbs the UV energy before it reaches the earth's surface. Some researchers have suggested that ozone photolysis to oxygen atoms could lead to the generation of hydroxyl radicals $(\cdot \mathrm{OH})$, a key reactive species during the decomposition process. ${ }^{5}$ Ozone decomposes producing hydroperoxyls $\left(\cdot \mathrm{HO}_{2}\right)$, hydroxyls $(\cdot \mathrm{OH})$, and superoxides $\left(\cdot \mathrm{O}_{2}^{-}\right)$radicals. ${ }^{6-8}$ The hydroxyl radical is an important transient species and chain-propagating radical. The reactivity of ozone is attributed to the great oxidizing power of these free radicals. According to some authors, the rate constants for reactions of $\mathrm{OH}$ radical with many substrates are very high. Consequently, these radicals are consumed preferentially by dissolved species before they encounter dispersed particles such as microorganisms. This occurs even when concentrations of molecular solutes are smaller than those of the particles. In many systems, however, $\mathrm{OH}$ radicals react with solutes to form secondary intermediates of lower reactivity (for example, peroxy radicals) that may survive until they encounter a dispersed particle. ${ }^{7}$

\section{AirPHX "tubular corona technology"}

AirPHX's technology is capable of producing a stable coronal ionic discharge (a plasma) using a proprietary and patented electromechanical device. The plasma field is created along the inside and outside of a tubular dielectric which is composed of pairs of cylindrical wire mesh electrodes (an anode and a cathode) placed inside and outside of a tubular insulator. When electrical power is applied to these electrodes, a stable, non-thermal corona is produced along the entire extent of the tubular dielectric which generates plasma. The fact that this plasma can be created at varying external temperatures, varying relative humidity, in the absence of a vacuum or noble gases, and with low and high energy dielectric tubes in the same reaction chamber are all unique features of airPHX's technology.

AirPHX's equipment creates a stable, non-collapsing, nondrifting "tubular corona discharge" within its reaction chamber (Figure 2). Traditional systems generate a large amount of heat due to inefficiency in production of the plasma field. AirPHX technology does not increase the ambient temperature. Hence, airPHX units create "non-thermal" plasma.

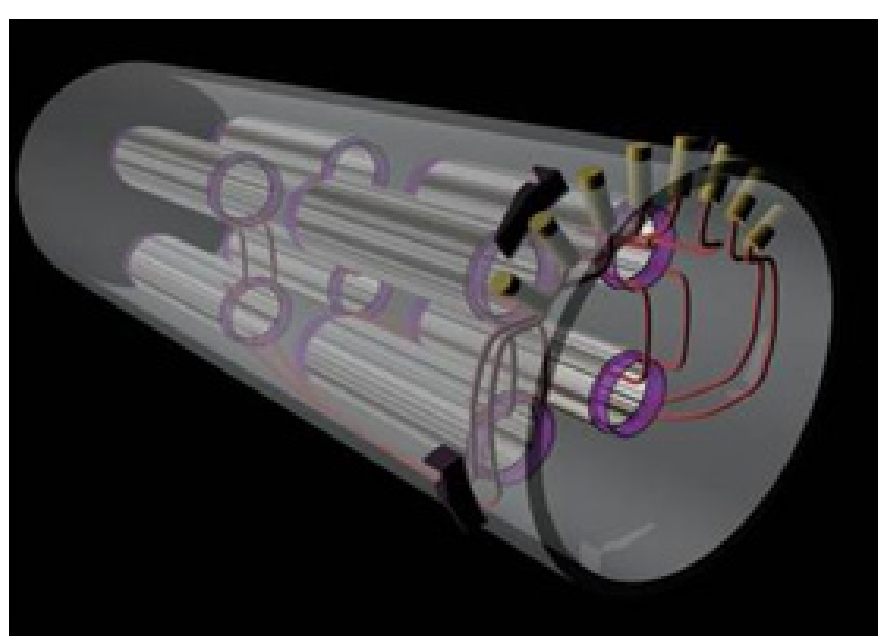

Figure 2 "Tubular corona” technology.
When air is drawn through the plasma in a reaction chamber, a small number of the oxygen molecules present are converted into a number of oxygen based oxidizing molecules that are referred to as "Reactive Oxygen Species" (ROS).

These ROS include oxygen ions, free radicals and peroxides that are highly reactive due to the presence of an unpaired valence shell electron. It is important to note that the amount of energy present in the airPHX plasma is not strong enough to alter the nitrogen in the air.

Measurable levels of gas-phase hydrogen peroxide, other ROS, and ozone are produced within the chamber and, given their halflives, can be allowed to enter the surrounding environment when this is desired. The hydrogen peroxide produced is different than vaporized or aerosolized hydrogen peroxide. Gas-phase hydrogen peroxide has a more acute bond angle and is shorter lived than the more stable liquid or vaporized forms. In addition, the ozone produced is shorter lived with an approximate 20 minute half life. When ozone is released from an airPHX unit based on the intended use, it interacts with airborne contamination and is consequently at very low dissolved levels. It is reasonable to assume that a number of other ROS are created within the chamber but do not leave it due their short half-lives:

\begin{tabular}{ll}
\hline Species & Half Life \\
\hline Atomic Oxygen $(\mathrm{O})$ & microseconds \\
Singlet Oxygen $\left(\mathrm{O}_{2}\right.$ with displaced electron) & microseconds \\
Hydroxyl Radicals $\left(\mathrm{OH}^{-}\right)$ & microseconds \\
Superoxide $\left(\mathrm{O}^{2-)}\right.$ & $<\mathrm{I} \mathrm{sec}$ \\
Hydrogen Peroxide $\left(\mathrm{H}_{2} \mathrm{O}_{2}\right)$ & Variable \\
Ozone $\left(\mathrm{O}_{3}\right)$ & 20 minutes max-carbon \\
\end{tabular}

The technology developed by airPHX has a wide range of applications because of its ability to produce a highly oxidative environment within its reaction chamber and its ability to discharge molecules that have an oxidizing capacity at levels that are safe for human exposure into the environment (Ozone, hydrogen peroxide and other ROS).

The range of applications is enhanced because the equipment can be scaled and modified to meet client's particular needs by:

a) Varying the size and number of tubular dielectrics within a reaction chamber

b) Modifying the power supply to change the components of the ROS formed

c) Passing the discharge from the unit through a catalyst or series of catalysts to eliminate or reduce the discharge of an ROS from the unit.

\section{Antimicrobial action of reactive oxygen species and ozone $\left(\mathrm{O}_{3}\right)$}

Reactions of ozone with various chemical compounds in aqueous systems occur in two different and coexisting modes, one involving direct reactions of molecular ozone and the other being a free radicalmediated destruction mode. ${ }^{9}$ Singlet oxygen is a likely intermediate reactive species in the biochemical damage caused by ozone. ${ }^{10}$ These multiple mechanisms may apply also to the destructive effect of ozone on bacteria. 
It has been proposed that the bacterial cell surface is the primary target of ozone activity. ${ }^{11,12}$ Found some leakage of cell contents with ozone treatment, so they proposed as the primary site of attack the double bonds of unsaturated lipids in the cell envelope.

Murray et al. ${ }^{13}$ assumed that lipoprotein and lipopolysaccharide layers of gram-negative bacteria would be subjected first to attack by ozone that results in a change in cell permeability, eventually leading to lysis. Bancroft \& Richter ${ }^{14}$ believe that ozone causes cellular proteins to flocculate, and Bringman ${ }^{15}$ that chlorine selectively destroys certain enzymes, whereas ozone acted as a general protoplasmic oxidant. Ingram \& Haines ${ }^{16}$ found a general destruction of the dehydrogenating enzyme systems and proposed that death of the cell may result from interference with the respiratory system. Barron ${ }^{17}$ suggested that the oxidation of sulfhydryl groups (SH- to $\mathrm{S}-\mathrm{S})$ in the enzyme is the principal cause of death. Other authors have suggested that Ozone may inactivate microorganisms by causing damage to their genetic material by modifying the pyrimidine bases on the DNA. ${ }^{18}$ Ozone inactivates numerous bacteria that include gram-negative and gram-positive and both vegetative cells and spore forms (Table 1). An often-cited disadvantage of using ozone as a disinfectant is that, unlike chlorine, it is extremely unstable. ${ }^{19}$ It is difficult to predict how ozone reacts in the presence of organic matter. It can oxidize or ionize the compound, or spontaneously decompose to oxygen and free radicals. Mechanisms of decomposition of ozone are complex processes that depend on factors such as the types of radicals formed in solution and various types of organic matter present in the medium that initiate, promote, or inhibit the radical chain reaction. Therefore, it may be difficult to generalize that a particular concentration of ozone at a given rate will always be effective in inhibiting a definite concentration of microorganisms. ${ }^{20-22}$

Table I Inactivation of bacteria by ozone

\begin{tabular}{|c|c|c|c|c|c|c|c|c|}
\hline Bacterium & $\begin{array}{l}\text { Inactivation } \\
(\log 10)\end{array}$ & $\begin{array}{l}\text { Treatment Time } \\
\text { (min) }\end{array}$ & $\begin{array}{l}\text { Concentration } \\
\text { (mg/liter) }\end{array}$ & $\mathbf{P H}$ & $\begin{array}{l}\text { Temp } \\
\left({ }^{\circ} \mathrm{C}\right)\end{array}$ & Medium & $\begin{array}{l}\text { Reactor } \\
\text { Type }\end{array}$ & Reference \\
\hline Bacillus Cereus & $>2.0$ & 5 & 0.12 & & 28 & $\begin{array}{l}03 \text { demand-free } \\
\text { water }\end{array}$ & & 22 \\
\hline B Cereus (Spores) & $>2.0$ & 5 & 2 & & 28 & $\begin{array}{l}03 \text { demand-free } \\
\text { water }\end{array}$ & & 22 \\
\hline Escherichia Coli & 4 & 2 & $0.23-0.26$ & 7 & 24 & $\begin{array}{l}03 \text { demand-free } \\
\text { water }\end{array}$ & $\begin{array}{l}\text { Continuous } \\
\text { flow }\end{array}$ & 56 \\
\hline E. Coli & 3 & 19 & $\begin{array}{l}\text { Initial 2.2, residual } \\
0.06\end{array}$ & 8 & 16 & Raw waste water & $\begin{array}{l}\text { Continuous } \\
\text { flow }\end{array}$ & 100 \\
\hline E. Coli & 2 & 0.1 & 0.53 & 7 & I & Phosphate buffer & Batch & 60 \\
\hline $\begin{array}{l}\text { Legionella } \\
\text { Pneumophila }\end{array}$ & $>4.5$ & 20 & 0.32 & 7 & 24 & Distilled water & Batch & 50 \\
\hline $\begin{array}{l}\text { Mycobacterium } \\
\text { Fortuitum }\end{array}$ & 1 & 2 & $0.23-0.26$ & 7 & 24 & $\begin{array}{l}03 \text { demand-free } \\
\text { water }\end{array}$ & $\begin{array}{l}\text { Continuous } \\
\text { flow }\end{array}$ & 56 \\
\hline $\begin{array}{l}\text { Pseudomonas } \\
\text { Fluorescens }\end{array}$ & $>2.0$ & 0.25 & & & & & & 27 \\
\hline $\begin{array}{l}\text { Salmonella } \\
\text { Enteritidis }\end{array}$ & I & 0.25 & $8 \%(w t / w t)$ & & 25 & Broiler carcass & Ozone gas & 153 \\
\hline $\begin{array}{l}\text { Salmonella } \\
\text { Typhimurium }\end{array}$ & 4 & 2 & $0.23-0.26$ & 7 & 24 & $\begin{array}{l}03 \text { demand-free } \\
\text { water }\end{array}$ & $\begin{array}{l}\text { Continuous } \\
\text { flow }\end{array}$ & 56 \\
\hline $\begin{array}{l}\text { Staphylococcus } \\
\text { Estrous }\end{array}$ & $>2.0$ & 0.25 & & 7 & 25 & Phosphate buffer & $\begin{array}{l}\text { Batch } \\
\text { (bubbling) }\end{array}$ & 27 \\
\hline
\end{tabular}

Hydrogen peroxide $\left(\mathrm{H}_{2} \mathrm{O}_{2}\right)$ is a very pale blue liquid, slightly more viscous than water, which appears colorless in dilute solution. It is a weak acid, has strong oxidizing properties, and is a powerful bleaching agent. It is used as a disinfectant, antiseptic, oxidizer, and in rocketry as a propellant. The oxidizing capacity of hydrogen peroxide is so strong that it is considered a highly reactive oxygen species. Its reactions tend to occur via radical paths, but it is easy to understand the reactivity if you imagine the $\mathrm{HOOH}$ to split into $\mathrm{OH}^{-}$and $\mathrm{OH}^{+}$; the $\mathrm{OH}^{+}$would of course be the oxidizing agent, as it desperately needs electrons. ${ }^{23}$

The antimicrobial effects of gaseous hydrogen peroxide have not been as extensively studied as other antimicrobials; however, a recent study investigated the effectiveness of a new gaseous hydrogen peroxide sterilization process for prions as an alternative low-temperature method. Gaseous peroxide, in addition to known antimicrobial efficacy, was shown to inactivate prions both in in-vitro and in-vivo assays. In contrast to the gas form, liquid peroxide was not effective. The mechanism of action of gaseous peroxide suggested protein unfolding, some protein fragmentation and higher sensitivity to proteolytic digestion. Hydrogen peroxide liquid showed a degree of protein clumping and full resistance to protease degradation. The use of gaseous peroxide in a standard low-temperature sterilization process may present a useful method for prion inactivation. ${ }^{24}$

Hydrogen peroxide is a strong oxidizer. It is more powerful than chlorine $\left(\mathrm{Cl}_{2}\right)$, chlorine dioxide $\left(\mathrm{ClO}_{2}\right)$ and potassium permanganate $\left(\mathrm{KMnO}_{4}\right)$. 
Through catalysis, hydrogen peroxide can be converted into hydroxyradicals $(\mathrm{OH})$. The oxidation potential of hydrogen peroxide (1.8) is just below that of ozone (2.1). The disinfection mechanism of hydrogen peroxide is based on the release of free oxygen radicals: $\mathrm{H}_{2} \mathrm{O}_{2}$ $\rightarrow \mathrm{H}_{2} \mathrm{O}+\mathrm{O}_{2}$ Pollutions are decomposed by free oxygen radicals, and only water remains. Free radicals have both oxidizing and disinfecting abilities. Hydrogen peroxide eliminates proteins through oxidation and laboratory tests with bacteria show that hydrogen peroxide is mutagenic; it changes and damages DNA..$^{25}$

\section{Objective}

The objective of this study was to evaluate the effectiveness of ROS exposure for reducing bacterial populations of Clostridium difficile, Methicillin Resistant Staphylococcus aureus (mRSA) and Pseudomonas aeruginosa on three (3) common contact surfaces; stainless steel, plastic (PVC) and linoleum (floor tile)

\section{Material and methods}

\section{Surfaces evaluated}

Surgical stainless steel is an informal term which refers to certain grades of stainless steel that are used in biomedical applications. The most common "surgical steels" are austenitic 316 stainless and martensitic 440 and 420 stainless steels. There is no formal definition on what constitutes a "surgical stainless steel" so product manufacturers and distributors apply the term to refer to any grade of corrosion resistant steel. Austenitic 316 stainless was used in these trials.

Plastic, traditionally, metals, glass and ceramics were used for medical implants, devices and supports. However, polymers are better suited to these applications as they offer lighter weight, better biocompatibility and lower cost. Fibers and resins used in medical applications include polyvinyl chloride (PVC), polypropylene (PP), polyethylene (PE), polystyrene (PS) as well as nylon, polyethylene terephthalate (PET), polyimide (PA), polycarbonate (PC), acrylonitrile butadiene (ABS), polyetheretherketone (PEEK) and polyurethane (PU).

The most widely used plastic material in medical applications is PVC followed by PE, PP, PS and PET. PVC most widely used in pre-sterilized single use medical applications. PVC was used in these trials.

Hospital flooring needs to be durable, resilient, and slip-free. Flooring decisions need to be made for different areas of the hospital; the waiting room would need a different flooring type than operating rooms. Traditionally, VCT, or vinyl composition tile, has been the most widely used flooring in hospitals. It is one of the most popular types of flooring for hospitals because it is sanitary, easy to clean, and easy to repair. VTC was used in these trials.

Contact surfaces mentioned above were cut to $4 \mathrm{~cm}$ round coupons. An appropriate number was prepared to complete triplicate evaluations for treated inoculated coupons and controls (non-treated coupons). Prior to inoculation, binder clips, cooling racks, and surfaces were cleaned using Fisher brand $*$ Sparkleen* detergent $(\mathrm{pH}$ 9.5-10 in solution, Fisher Scientific), rinsed with de-ionized water and sterilized by autoclaving with their corresponding binder clip. Both chambers were cleaned and sanitized prior to introducing the coupons.

\section{Microbiological cultures}

\section{a) $\mathrm{mRSA}$}

Bacterial culture utilized was ATCC 33591 and cultured per manufacturer's instructions using Tryptic Soy Broth (TSB, Difco $\left.{ }^{\circledR}\right)$ and incubated for $18-20 \mathrm{~h}$ in aerobic conditions at $37.0^{\circ} \mathrm{C}$ and was subsequently enumerated on Trypticase Soy Agar (TSA, Difco ${ }^{\circledR}$ ) and Baird Parker Agar (BPA, Difco $\left.{ }^{\circledR}\right)$

\section{b) Clostridium difficile}

ATCC BAA-1382D-5 was the bacteria culture utilized cultured in Brain Heart Infusion medium with yeast extract, (BHIS, Difco ${ }^{\circledR}$ ) plates and broth. All plates were incubated anaerobically for $48 \mathrm{~h}$ at $37^{\circ} \mathrm{C}$ and enumerated on BHIS and Clostridium difficile Selective Agar (CDSA, Becton Dickinson)

\section{c) Pseudomonas aeruginosa}

ATCC 27853 was employed, and was cultured per manufacturer's instructions using Tryptic Soy Broth (TSB, Difco ${ }^{\mathbb{R}}$ ) and incubated for $18-20 \mathrm{~h}$ in aerobic conditions at $37.0^{\circ} \mathrm{C}$ and was subsequently enumerated on Trypticase Soy Agar (TSA, Difco ${ }^{\circledR}$ ) and Cetrimide Selective Agar (CSA, Hardy Diagnostics)

After incubation, each of the microbial cultures was washed by centrifugation at 13,300 RPM for 10min, and re-suspension of the pellet in $0.1 \%$ peptone water. Next, the inoculum was composited in a single $50 \mathrm{ml}$ cocktail. Twenty seven coupons each per organism were inoculated by evenly spreading $0.1 \mathrm{ml}$ of the inoculum on the entire surface of one side of the $4 \mathrm{~cm}$ coupon. Each coupon was individually isolated from the chamber surface by placing it on a petri lid. Coupons were allowed to dry for $1 \mathrm{~h}$. Inoculum levels and attachment to the surfaces was confirmed by enumeration on selective agars. The target attachment level for the inoculum on the surfaces was $7-8 \log _{10} \mathrm{CFU} /$ $\mathrm{cm}^{2}$.

\section{Treatment}

Two biosafety chambers were used to isolate the coupons placed inside a petri dish during the exposure of the stainless steel surfaces to ROS. Inside the chamber was fixed a RELI ON humidifier Cool Mist RCM-832 (Kaz Incorporated, Southborough, MA) to uniformly control the Relative Humidity (RH). Temperature (T) and relative humidity inside the chamber were monitored with an aeroQUAL series 500 sensor (aeroQUAL Limited, Aukland, New Zealand) monitoring $\mathrm{O}_{3}$ as an indicator of ROS production). Temperature and relative humidity were monitored constantly with an Acu-Rite monitor Model 00613 (Acu-Rite Companies Inc., Jamestown, NY). Target $\mathrm{T}$ and $\mathrm{RH}$ were between $25-27^{\circ} \mathrm{C}$ and $\mathrm{RH}$ between $50-80 \%$, respectively.

A set of three random coupons, per organism were tested immediately ( 0 hour) to determine the attachment level to the selected surfaces. In addition, four sets of three coupons (randomly selected) per organism were placed inside the chamber in a $30^{\circ}$ angle using a binder clip (Staples, USA).

The twelve coupons per organism placed inside the experimental chamber were continuously treated with ROS at $0.04-0.05 \mathrm{ppm}$ for $0.5,1,2,4,6,8,12$ and 24 hours with an advanced oxidation generator (airPHX, Arlington, VA). Chamber was allowed to stabilize at desired ROS $(0.04-0.05 \mathrm{ppm})$, relative humidity $(50-60 \%)$ and temperature levels $\left(25-30^{\circ} \mathrm{C}\right)$ prior to introducing the coupons. ROS levels were continuously monitored with a 1 minute frequency with an AeroQual 
Series 500 sensor and confirmed with $0.01-0.1 \mathrm{ppm}$ Drager tubes (Drager Safety USA) for ROS (ozone and for hydrogen peroxide) prior to removing coupons for microbiological testing. The twelve remaining coupons (controls) per organism were similarly placed in a control chamber and held at environmental conditions to determine natural decay of microbial populations through time. After removing coupons, chambers were allowed to re-stabilize at target levels of experimental parameters to minimize experimental variability in the chamber environment.

Samples (inoculated and controls) were aseptically collected for microbiological analysis at designated times $(0.5,1,2,4,6,8$, 12 and 24 hours) after completion of treatment process. Coupons by organism were individually placed inside a sterile centrifuge tube with $15 \mathrm{ml}$ of $0.1 \%$ peptone and vortexed for $2 \mathrm{~min}$. Serial dilutions $(0-5)$ were made and $0.1 \mathrm{ml}$ spread plated onto duplicate pour plates. Plates were incubated at the respective temperature and time for each organism. Populations were calculated and reported as $\log _{10} \mathrm{CFU} /$ coupon. Reductions were calculated by obtaining the difference between populations recovered on the selective agar at each exposure time and the initial attachment level of the inoculum.

\section{Results and discussion}

\section{Methicillin resistant staphylococcus aureus (mRSA)}

Table $2 \& 3$ show $m R S A$ recoveries in Baird Parker Agar for the control (non-treated) coupons and the treated coupons after 0, 0.5, $1,2,4,6,8,12$ and 24 hours exposure to $0.04-0.05 \mathrm{ppm}$ ROS, respectively.

Table 2 mRSA Recoveries in baird parker agar for the control (non-treated) coupons

\begin{tabular}{lllll}
\hline \multirow{2}{*}{ Time } & \multicolumn{2}{l}{ mRSA recovery } & \multicolumn{2}{l}{ Cumulative } \\
\cline { 2 - 4 } & \multicolumn{2}{l}{ Non-treated SS coupons } & reduction \\
\cline { 2 - 3 } & CFU & Log & SD & \\
\hline 0 & $53,000,000$ & 7.72 & 0.1 & - \\
0.5 & $50,000,000$ & 7.7 & 0.2 & 0.02 \\
1 & $48,500,000$ & 7.69 & 0.1 & 0.03 \\
2 & $46,050,000$ & 7.66 & 0.1 & 0.06 \\
4 & $43,500,000$ & 7.64 & 0.2 & 0.08 \\
6 & $40,950,000$ & 7.61 & 0.2 & 0.11 \\
8 & $39,900,000$ & 7.6 & 0.1 & 0.12 \\
12 & $38,500,000$ & 7.59 & 0.1 & 0.11 \\
24 & $37,000,000$ & 7.57 & 0.2 & 0.13 \\
\hline
\end{tabular}

The initial level of attachment for mRSA on the coupons was 7.72log. Results from the control chamber showed mRSA populations only decayed $0.08-\log$ to a level of 7.64- $\log$ over a period of 4 hours, only to recover to a final 7.59- $\log$ level, for a decay of $0.13-\log$ after 24 hours.

The reduction over exposure time for the three (3) surfaces, floor tile, plastic and stainless steel is graphically represented in Figure 3. The antimicrobial effects attributed to ROS on bacterial populations of $m R S A$ were calculated as the difference between the total reductions obtained by the treatment and the natural decline caused by the environmental conditions inside both chambers. Table 2 shows the antimicrobial effects on stainless steel coupons attributable to ROS with selected target levels.

Table $3 m R S A$ recoveries in baird parker agar for the treated coupons

\begin{tabular}{|c|c|c|c|c|}
\hline \multirow[t]{3}{*}{ Time } & \multicolumn{2}{|c|}{$m R S A$ recovery } & \multirow[b]{3}{*}{ SD } & \multirow{3}{*}{$\begin{array}{l}\text { Cumulative } \\
\text { reduction }\end{array}$} \\
\hline & \multicolumn{2}{|c|}{ Treated SS coupons } & & \\
\hline & CFU & $\log$ & & \\
\hline 0 & $53,000,000$ & 7.72 & 0.1 & - \\
\hline 0.5 & 3,500 & 3.51 & 0.2 & 4.21 \\
\hline I & 246 & 2.39 & 0.3 & 5.33 \\
\hline 2 & 129 & 2.11 & 0.2 & 5.61 \\
\hline 4 & 32 & 1.51 & 0.2 & 6.21 \\
\hline 6 & 13 & 1.11 & 0.1 & 6.61 \\
\hline 8 & 6 & 0.78 & 0.2 & 6.94 \\
\hline 12 & 7 & 0.85 & 0.3 & 6.87 \\
\hline 24 & 6 & 0.78 & 0.2 & 6.94 \\
\hline
\end{tabular}

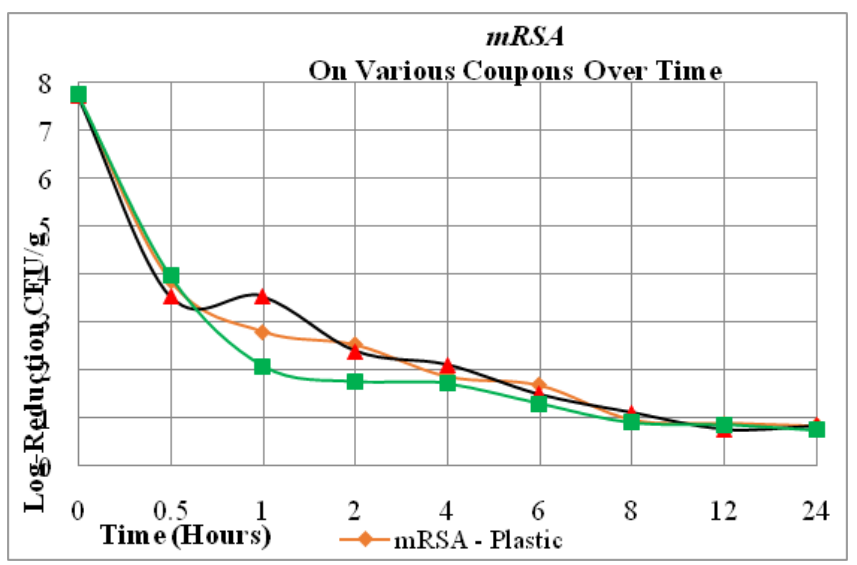

Figure 3 Recoveries of $m R S A$ populations on floor tile, plastic and stainless steel coupons exposed to 0.04 to 0.05 ppm ROS.

After 0.5 hour of exposure to ROS, $m R S A$ population declined from 7.72 to $3.51-\log$ on the treated coupons surfaces, showing a $4.21-\log$ decrease. The non-treated coupons also showed an insignificant 0.02 $\log$ reduction on bacterial populations, thus reduction levels attributed to ROS after 0.5 hour were $4.19-\log$. Similarly, exposure to ROS for 4 hours at targeted levels proved to have very effective antimicrobial on the stainless steel coupons, with $6.21-\log$ reductions were observed during that period of time. After 8 hours, ROS at the selected concentration had some additional effect on $m R S A$ populations, with a 6.94-log reduction. Nevertheless, after 24 hours exposure to such low levels of ROS, the technology showed excellent antibacterial effects reaching a cumulative lethality level of $6.94-\log$ on the challenged stainless steel coupons.

\section{Clostridium difficile}

Tables 4 and 5 show $m R S A$ recoveries in Clostridium difficile Selective Agar for the control (non-treated) coupons and the treated coupons after $0,0.5,1,2,4,6,8,12$ and 24 hours exposure to $0.04-0.05 \mathrm{ppm}$ ROS, respectively.

The initial level of attachment for Clostridium difficile on the coupons was 7.65-log. Results from the control chamber showed 
mRSA populations only decayed $0.01-\log$ to a level of 7.64- log over a period of 4 hours, only to recover to a final 7.62-log level, for a decay of $0.03-\log$ after 24 hours. The reduction over exposure time for the three (3) surfaces, floor tile, plastic and stainless steel is graphically represented in Figure 4. The antimicrobial effects attributed to ROS on bacterial populations of Clostridium difficile were calculated as the difference between the total reductions obtained by the treatment and the natural decline caused by the environmental conditions inside both chambers. Table 4 shows the antimicrobial effects on stainless steel coupons attributable to ROS with selected target level.

Table 4 Recoveries in clostridium difficile selective agar for the control (nontreated) coupons

\begin{tabular}{lllll}
\hline \multirow{2}{*}{ Time } & \multicolumn{2}{l}{ C. Difficile recovery } & \multicolumn{2}{l}{ Cumulative } \\
\cline { 2 - 4 } & \multicolumn{2}{l}{ Non-treated SS coupons } & reduction \\
\cline { 2 - 3 } & CFU & Log & SD & \\
\hline 0 & $44,652,250$ & 7.65 & 0.1 & - \\
0.5 & $44,125,250$ & 7.64 & 0.2 & 0.01 \\
1 & $43,745,500$ & 7.64 & 0.2 & 0.01 \\
2 & $43,258,410$ & 7.64 & 0.1 & 0.01 \\
4 & $43,576,500$ & 7.64 & 0.1 & 0.01 \\
6 & $43,150,250$ & 7.63 & 0.1 & 0.01 \\
8 & $42,989,500$ & 7.63 & 0.1 & 0.02 \\
12 & $42,801,200$ & 7.63 & 0.2 & 0.02 \\
24 & $42,105,250$ & 7.62 & 0.1 & 0.03 \\
\hline
\end{tabular}

Table 5 Recoveries in clostridium difficile selective agar for the treated coupons

\begin{tabular}{|c|c|c|c|c|}
\hline \multirow[t]{3}{*}{ Time } & \multirow{2}{*}{\multicolumn{2}{|c|}{$\begin{array}{l}\text { C. difficile recovery } \\
\text { Treated SS coupons }\end{array}$}} & \multirow[b]{3}{*}{ SD } & \multirow{3}{*}{$\begin{array}{l}\text { Cumulative } \\
\text { reduction }\end{array}$} \\
\hline & & & & \\
\hline & CFU & Log & & \\
\hline 0 & $44,668,359$ & 7.65 & 0.1 & - \\
\hline 0.5 & I,698 & 3.23 & 0.2 & 4.42 \\
\hline 1 & 481 & 2.68 & 0.1 & 4.97 \\
\hline 2 & 110 & 2.04 & 0.1 & 5.61 \\
\hline 4 & 26 & 1.42 & 0.1 & 6.24 \\
\hline 6 & 15 & 1.18 & 0.2 & 6.47 \\
\hline 8 & 8 & 0.9 & 0.1 & 6.75 \\
\hline 12 & 3 & 0.48 & 0.2 & 7.17 \\
\hline 24 & 2 & 0.3 & 0.2 & 7.35 \\
\hline
\end{tabular}

After 0.5 hour of exposure to ROS, Clostridium difficile population declined from 7.65 to $3.23-\log$ on the treated coupons surfaces, showing a 4.42-log decrease. The non-treated coupons also showed an insignificant $0.01-\log$ reduction on bacterial populations, thus reduction levels attributed to ROS after 0.5 hour were $4.41-\log$. Similarly, exposure to ROS for 4 hours at targeted levels proved to have very effective antimicrobial on the stainless steel coupons, with 6.24-log reductions were observed during that period of time. After 8 hours, ROS at the selected concentration had some additional effect on Clostridium difficile populations, with a 6.75-log reduction. Nevertheless, after 24 hours exposure to such low levels of ROS, the technology showed excellent antibacterial effects reaching a cumulative lethality level of $7-\log$ on the challenged stainless steel coupons.

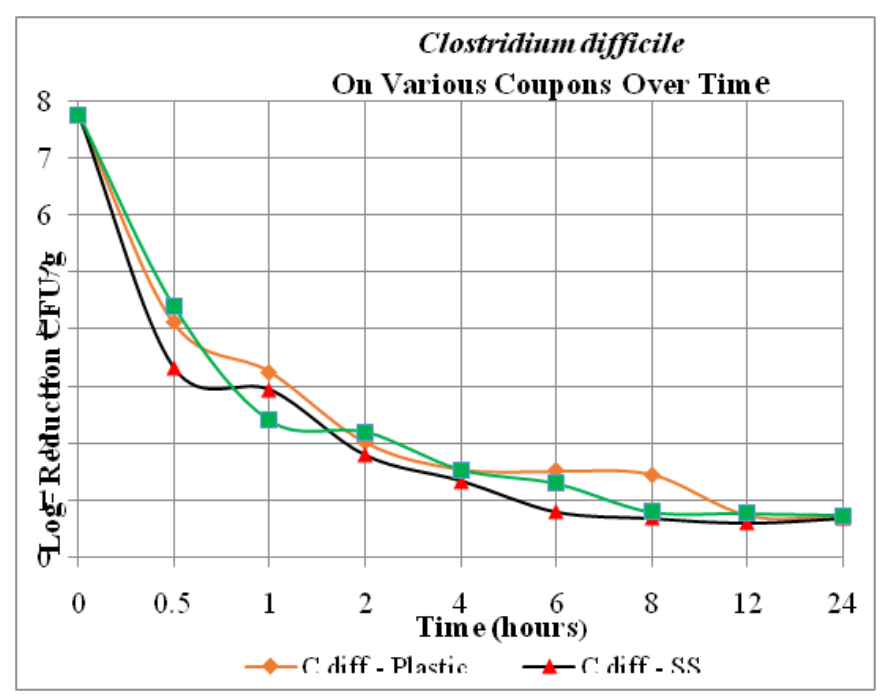

Figure 4 Recoveries of clostridium difficile populations on floor tile, plastic and stainless steel coupons exposed to 0.04 to 0.05 ppm ROS.

\section{Pseudomonas aeruginosa}

Tables 5 and 6 show Pseudomonas aeruginosa recoveries in Cetrimide Selective Agar for the control (non-treated) coupons and the treated coupons after $0,0.5,1,2,4,6,8,12$ and 24 hours exposure to $0.04-0.05 \mathrm{ppm}$ ROS, respectively

Table 6 Recoveries in cetrimide selective agar for the control (non-treated) coupons

\begin{tabular}{lllll} 
Time & \multicolumn{2}{l}{ P. aeruginosa recovery } & \multicolumn{2}{l}{ Cumulative } \\
& \multicolumn{2}{l}{ Non-treated SS coupons } & reduction \\
& CFU & Log & SD & \\
\hline 0 & $56,254,500$ & 7.75 & 0.2 & - \\
0.5 & $56,500,120$ & 7.75 & 0.1 & 0 \\
I & $55,985,500$ & 7.75 & 0.2 & 0 \\
2 & $56,015,200$ & 7.75 & 0.2 & 0 \\
4 & $55,874,500$ & 7.75 & 0.1 & 0 \\
6 & $55,750,500$ & 7.75 & 0.1 & 0 \\
8 & $55,540,500$ & 7.74 & 0.1 & 0.01 \\
12 & $54,982,400$ & 7.74 & 0.1 & 0.01 \\
24 & $55,050,200$ & 7.74 & 0.1 & 0.01 \\
\hline
\end{tabular}

The initial level of attachment for Pseudomonas aeruginosa on the coupons was 7.75-log. Results from the control chamber showed Pseudomonas aeruginosa populations only decayed $0.00-\log$ to a level of 7.75-log over a period of 4 hours, only to recover to a final 7.74- $\log$ level, for a decay of $0.01-\log$ after 24 hours. The reduction over exposure time for the three (3) surfaces, floor tile, plastic and stainless steel is graphically represented in Figure 5. The 
antimicrobial effects attributed to ROS on bacterial populations of Pseudomonas aeruginosa were calculated as the difference between the total reductions obtained by the treatment and the natural decline caused by the environmental conditions inside both chambers. Table 7 shows the antimicrobial effects on stainless steel coupons attributable to ROS with selected target levels

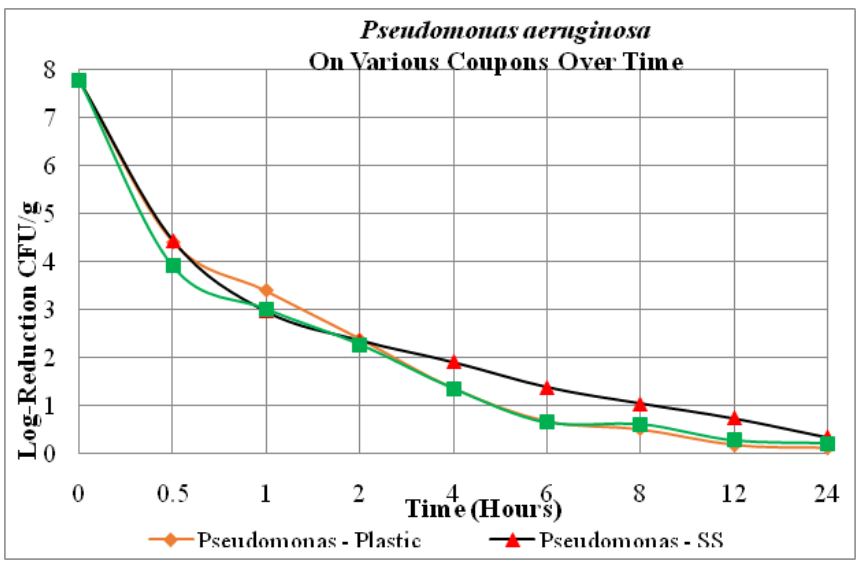

Figure 5 Recoveries of Pseudomonas aeruginosa populations on floor tile, plastic and stainless steel coupons exposed to 0.04 to 0.05 ppm ROS.

Table 7 Recoveries in cetrimide selective agar for the treated coupons

\begin{tabular}{|c|c|c|c|c|}
\hline \multirow[t]{3}{*}{ Time } & \multirow{2}{*}{\multicolumn{2}{|c|}{$\begin{array}{l}\text { P. aeruginosa recovery } \\
\text { Treated SS coupons }\end{array}$}} & \multirow[b]{3}{*}{ SD } & \multirow{3}{*}{$\begin{array}{l}\text { Cumulative } \\
\text { reduction }\end{array}$} \\
\hline & & & & \\
\hline & CFU & Log & & \\
\hline 0 & $52,500,000$ & 7.72 & 0.1 & - \\
\hline 0.5 & 2,913 & 3.46 & 0.2 & 4.26 \\
\hline 1 & 845 & 2.93 & 0.2 & 4.79 \\
\hline 2 & 205 & 2.31 & 0.1 & $5.4 I$ \\
\hline 4 & 75 & 1.88 & 0.1 & 5.84 \\
\hline 6 & 22 & 1.34 & 0.2 & 6.38 \\
\hline 8 & 10 & 1 & 0.1 & 6.72 \\
\hline 12 & 5 & 0.7 & 0.1 & 7.02 \\
\hline 24 & 2 & 0.3 & 0.1 & 7.42 \\
\hline
\end{tabular}

After 0.5 hour of exposure to ROS, Pseudomonas aeruginosa population declined from 7.72 to $3.46-\log$ on the treated coupons surfaces, showing a 4.26-log decrease. The non-treated coupons also showed no $\log$ reduction on bacterial populations, thus reduction levels attributed to ROS after 0.5 hour were 4.26-log. Similarly, exposure to ROS for 4 hours at targeted levels proved to have very effective antimicrobial on the stainless steel coupons, with 5.84-log reductions were observed during that period of time. After 8 hours, ROS at the selected concentration had some additional effect on Pseudomonas aeruginosa populations, with a $6.72-\log$ reduction. Nevertheless, after 24 hours exposure to such low levels of ROS, the technology showed excellent antibacterial effects reaching a cumulative lethality level of 7.42-log on the challenged stainless steel coupons.

\section{Conclusion}

Based on these findings, our study reveals that reactive oxygen species treatment using the ROS-generating airPHX unit significantly reduces three HAI organisms on three common health care contact materials. Substantial log destruction was seen after the smallest exposure time of $0.5 \mathrm{~h}$. The ROS treatment is equally inhibitory to all three HAI microorganisms in this experiment. The unit has an application for controlling surface as well as airborne contamination, currently under investigation, in and not limited to, clinical, dental, surgical offices and hospital treatment.

\section{Acknowledgements}

None.

\section{Conflict of interest}

The author declares no conflict of interest.

\section{References}

1. Maryadele J O'Neil, Ann Smith, Patricia E Heckelman. The Merck index: an encyclopedia of chemicals, drugs, and biological / Susan Budavari. 11 th ed. Rahway, New Jersey, USA; 1989.

2. Brady JE, Humiston GE. General chemistry principles and structure. 2nd ed. New York: John Wiley \& Sons; 1978.

3. Horvath M, Bilitzky L, Huttner J. Fields of utilization of ozone. In: RJH Clark, editor. USA: Ozone Elsevier Science Publishing Co. Inc.; 1985. p. 257-316.

4. Ewell AW. Recent ozone investigation. Journal of Applied Physics. 1946;17(11):908-911.

5. Levy H. Normal atmosphere: large radical and formaldehyde concentrations predicted. Science. 1971;173(3992):141-143.

6. Grimes HD, Perkins KK, Boss WF. Ozone degrades into hydroxyl radical under physiological conditions: A Spin Trapping Study. Plant Physiology. 1983;72(4):1016-1020.

7. Hoigne J, H Bader. Ozonation of water: role of hydroxyl radicals as oxidizing intermediates. Science. 1975;190(4216):782-784.

8. Hoigne $\mathrm{J}, \mathrm{H}$ Bader. The role of hydroxyl radical reactions in ozonation processes in aqueous solutions. Water Research. 1976;10(5):377-386.

9. Staehelin J, Hoigne J. Decomposition of ozone in water in the presence of organic solutes acting as promoters and inhibitors of radical chain reactions. Environ Sci Technol. 1985;19(12):1206-1213.

10. Kanofsky JR, Sima P. Singlet oxygen production from the reactions of ozone with biological molecules. J Biol Chem . 1991;266(14):9039-9042.

11. Giese AC, Christenser E. Effects of ozone on organisms. Physiological Zoology. 1954;27(2):101-115.

12. Scott DB, Lesher EC. Effect of ozone on survival and permeability of Escherichia coli. J Bacteriol. 1963;85:567-576.

13. Murray RG, S Pamela, HE Elson. Location of mucopeptide of selection of the cell wall of $E$. coli and other gram negative bacteria. Canadian Journal of Microbiology. 1965;11(3):547-560.

14. Bancroft WD, GH Richter. The chemistry of disinfection. J Phys Chem. 1931;35(2):511-530.

15. Bringman G. Determination of lethal activity of chlorine and ozone on $E$. coli. Water Pollut Abstr. 1955;28:12.

16. Ingram $M, R B$ Haines. Inhibition of bacterial growth by pure ozone in the presence of nutrients. J Hyg (Lond). 1949;47(2):146-158.

17. Barron ES. The role of free radicals of oxygen in reactions produced by ionizing radiations. Radiation Research. 1954;1(1):109-124.

18. Prat R, Nofre C, Cier A. Effects of sodium hypochlorite, ozone and ionized radiation on the pyrimidine components of Escherichia coli. Ann Inst Pasteur Paris. 1968;114:595-607. 
19. Meddows-Taylor J. Some characteristics of ozone in relation to water treatment. J Inst Water Eng. 1947;1:187-201.

20. Jin-Gab Kim, Yousef Ahmed E, Dave Sandhya. Application of ozone for enhancing the microbiological safety and quality of foods: a review. $J$ Food Prot. 1999;62(9):1071-1087.

21. Rosen HM. Ozone generation and its relationship to the economical application of ozone in wastewater treatment. 3rd ed. USA: Ann Arbor Sci Publish Inc; 1972. p. 101-122.
22. Scott DB. The effect of ozone on nucleic acids and their derivatives In: WJ Blogoslawski, RG Rice, editors. Aquatic applications of ozone. USA: International Ozone Institute; 1975. p. 226-240.

23. Sweeting M Linda. Oxidizing Agents. 1988.

24. Fichet G, K Antloga, E Comoy, et al. Prion inactivation using a new gaseous hydrogen peroxide sterilization process. $J$ Hosp Infect. 2007;67(3):278-286.

25. Disinfectants Hydrogen peroxide. LennTech. 2009. 